\title{
Hydrosalinity fluxes in a small scale catchment of the Berg river (South Africa)
}

\author{
N. Z. Jovanovic ${ }^{1}$, R. D. H. Bugan ${ }^{2}$, G. Frantz ${ }^{2}$, W. de Clercq ${ }^{3}$ \\ $\& \mathrm{M} . \mathrm{Fey}^{3}$ \\ ${ }^{1}$ CSIR, Natural Resources and Environment, Stellenbosch, South Africa \\ ${ }^{2}$ Department of Earth Sciences, University of the Western Cape, \\ South Africa \\ ${ }^{3}$ Department of Soil Science, University of Stellenbosch, South Africa
}

\begin{abstract}
The occurrence of dryland salinity is widespread throughout semi-arid regions of the world. The sources of salts may be either rock weathering or rain deposition. Clearing of natural scrubland to make way for cultivated crops and pastures may also change the water balance, trigger salt mobilization and increase the salinity of water resources. These processes are suspected to be the main cause for salinization of the Berg river catchment (South Africa). The objective of this study was to determine the hydrosalinity fluxes associated with overland and subsurface (vadose zone) flow for different soils and land uses. For this purpose, the following data were collected during 2006 in a typical small scale catchment ( $\sim 40$ ha) located near the town of Riebeek West: weather data, hydrological and water quality measurements, soil water contents and chemistry. The climate of the area is Mediterranean with winter rainfall of about $350 \mathrm{~mm} \mathrm{a}^{-1}$. The chemical speciation of water and soil solution in the catchment is conservative, with $\mathrm{Na}^{+}$ and $\mathrm{Cl}^{-}$being the dominant ions. Soil water and salt contents varied seasonally. Due to the typical low intensity of rainfall, the fluxes of salts during individual runoff events were steady. Fluctuations in salinity due to local processes were buffered at a catchment scale. Uncultivated (bare) soil produced more runoff and higher salinity compared to pasture land. Overland flow varied between 3 and $18 \%$ of rainfall, mobilizing up to $24 \mathrm{~g} \mathrm{~m}^{-2}$ of salts during 2006 , depending on soil properties, slopes, rainfall intensity and duration, and antecedent moisture conditions. Subsurface fluxes of water and salts were estimated with the HYDRUS-2D model. Management practices at farm scale are required in order to reduce salt mobilization and salinization at catchment scale.

Keywords: Berg river, dryland salinity, hydrosalinity fluxes, runoff, throughflow.
\end{abstract}




\section{Introduction}

The occurrence of dryland salinity is widespread throughout semi-arid regions of the world. It is characterized by the presence of sick/dying vegetation, a decline in the vegetation cover density, and by the appearance of salt tolerant species, bare salty patches and the development of saline pools. The salts may either be a product of the weathering of rock minerals or they may be brought into the landscape from the ocean, by rain or wind $[1,2]$. The process of salinization may be accelerated by human activities. Anthropogenic impacts can be attributed to the clearing of natural perennial scrubland to make way for cultivated crops and pastures, thereby changing the water balance, raising the water table and mobilizing fossil connate salts $[3,4]$. This may result in a decline of soil productivity, farm incomes and land value; it may affect the salinity of water bodies resulting in losses of aquatic plants, riparian vegetation and wetland areas.

In South Africa, dryland salinity is common in the Berg river catchment. The Berg river rises in the Franschhoek and Jonkershoek mountains and flows in a northwesterly direction where it eventually discharges into the sea at Laaiplek (fig. 1). It is approximately $270 \mathrm{~km}$ long and has a catchment size of about 900 $\mathrm{km}^{2}$ [5]. The river is used to supply Cape Town and other West Coast towns with drinking water, whilst irrigated and dryland agriculture and industrial water users represent the backbone of the economy of the Western Cape Province. The geology of the Berg river basin is dominated by the Malmesbury Group shales (western banks) and the Table Mountain Group sandstones (eastern banks). The Malmesbury Group is a Proterozoic marine deposit comprising greywacke and phyllite beds, with beds and lenses of quartz schist, limestone and grit. The South African Department of Waters Affairs and Forestry has monitored Berg river water quality since the mid 1970's. Natural soil salinity has been identified as the source of some of the salts affecting its water quality [6, 7]. However, it is a possibility that clearing of indigenous vegetation, i.e. renosterveld, to make space for dryland wheat farming over the last century or more may have accelerated the process of salt mobilization and deterioration of water quality in the river $[8,9]$.

A fundamental study was therefore initiated in order to characterize the mechanisms of salt mobilization depending on climate, parent material, topography and land use practices in a small scale catchment. The specific objectives of the study were to determine the hydrosalinity fluxes associated with overland and subsurface (vadose zone) flow for different soils and land uses.

\section{Material and methods}

A suitable and representative experimental site was selected in the Goedertrou 40 ha small scale catchment (SSC). The catchment supports a diversity of vegetation types (pasture, dryland winter wheat, vineyard), land use practices (anti-erosion contours, shallow tillage to break up the surface crust) and bioclimatic conditions representative of the drier, lower reaches of the Berg river basin, where storage and potential discharge of salts are likely to be the greatest. 
The study area was located $3 \mathrm{~km} \mathrm{NE}$ of the town of Riebeek West $\left(33^{\circ} 21^{\prime} 07^{\prime \prime} \mathrm{S}\right.$; $18^{\circ} 52^{\prime} 03^{\prime \prime} \mathrm{E}$; elevation $100 \mathrm{~m}$ amsl), which is approximately $70 \mathrm{~km}$ north of Cape Town in the Western Cape Province (fig. 1). It is a semi-arid region, which receives approximately $350 \mathrm{~mm}$ of rainfall per annum, mainly in winter. Shallow residual soils with differing sand, clay and gravel contents generally overlie silcrete and a weathered zone of the Malmesbury Group in the SSC.

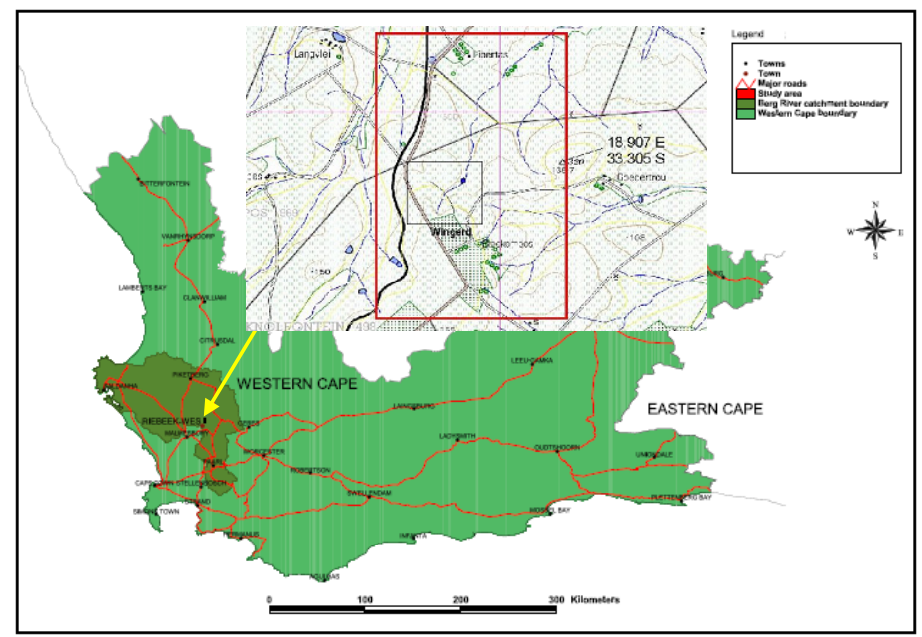

Figure 1: Study area: Berg river catchment (dark grey) as part of the Western Cape and location of the Goedertrou small scale catchment.

The land at Goedertrou was planted to winter wheat in 2005, and left fallow in 2006 to support the re-growth of wheat and medic grass (crops grown in previous seasons) for grazing. This is a common rotation in the area in order to somewhat regenerate soil fertility. Agronomic practices commonly used in the area were adopted. Due to the topographical characteristics, soil properties, land use, as well as the results of preliminary infiltration tests conducted in January 2005 , it was envisaged that the dominant processes in the SSC are runoff and throughflow. Intensive monitoring sites were therefore established in order to monitor water and salt fluxes via overland and subsurface flow.

The experimental scheme is shown in fig. 2 on a map representing elevation levels and anti-erosion contours. The low-lying drainage waterway runs in the middle of the map from right to left (to the dam). Runoff plots were established at sites 1 and 2 (fig. 2). Both sites were representative of areas between two manmade contours. The locations of these sites were in the vicinity of pits excavated for detailed soil analyses and boreholes. The runoff sites were chosen to represent two different, but typical hydrological units. Site 1 is North-oriented, whilst site 2 is South-East-oriented. The soils at the two sites are also different: $0.4 \mathrm{~m}$ deep sandy clay loam Glenrosa form [10] - Cambisol [11] - overlying 
Malmesbury shale at site 1; deep clay loam Swartland form [10] - Luvisol [11] at site 2 . The slope at site 1 is $9.1 \%$, whilst the slope at site 2 is $12.4 \%$.

Two standard Wischmeyer runoff plots were established, the one parallel to the other, at each runoff site (fig. 2). Each runoff plot covered an area of $44.6 \mathrm{~m}^{2}$ $(22.3 \mathrm{~m} \times 2 \mathrm{~m})$. At site 1, one runoff plot was kept under bare soil through regular application of the herbicide glyphosate, whilst the other was maintained to represent the surrounding conditions in the field. At site 2, both runoff plots were maintained to represent the surrounding conditions, but supported different vegetation densities and distributions. Fig. 2 also shows the location of the dam and weather station.

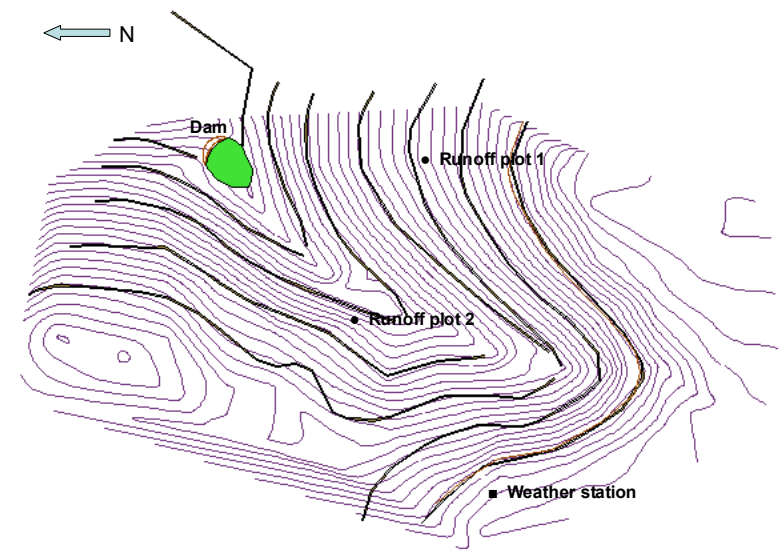

Figure 2: Experimental scheme at Goedertrou.

The following measurements were carried out at each runoff plot (sites 1 and 2):

Runoff water volumes and rainfall were measured with tipping buckets connected to MCS data loggers (Mike Cotton Systems, Cape Town, South Africa).

Runoff water quality was measured by collecting runoff water samples from two sediment collection tanks installed in sequence at the runoff plots.

An Eijkelkamp CTD-Diver and Baro-Diver were installed in the first tank of the bare soil runoff plot at site 1 with the aim of monitoring salinity and water level changes in the tank during single runoff events.

Soil physical properties (bulk density, porosity, water retention curves) and chemical properties were determined before monitoring started in each soil horizon in the vicinity of runoff plots. Changes in soil chemical properties were monitored by sampling monthly at $10 \mathrm{~cm}$ and $40 \mathrm{~cm}$ soil depth in the vicinity of the runoff plots.

Volumetric soil water content and salinity were measured electronically with EC-20 sensors connected to Echo loggers (Decagon Devices Inc.) in the vicinity of each runoff plot. The sensors were installed at depths of $10 \mathrm{~cm}$ and $40 \mathrm{~cm}$ at site 1 , and $10 \mathrm{~cm}$ and $50 \mathrm{~cm}$ at site 2 . The sensors were placed adjacent to the top and bottom of the runoff plots (eight sensors in total). 
Water quality was measured in dam and rain water samples.

Weather data (solar radiation, temperature, relative humidity and wind speed) were collected with an automatic weather station (Mike Cotton Systems, Cape Town, South Africa).

\section{Results}

Chemical analyses of water samples collected in the catchment (in runoff and dam water) indicated that water is dominated by $\mathrm{NaCl}$ and it is conservative in terms of ionic speciation. The relationship between total dissolved solids (TDS) and electrical conductivity (EC) was: TDS $[\mathrm{mg} / \mathrm{L}]=608.53 \mathrm{EC}[\mathrm{dS} / \mathrm{m}]-55.83$ $\left(\mathrm{R}^{2}=0.98\right)$. Similar results were obtained on samples of soil water extracts (TDS $\left.[\mathrm{mg} / \mathrm{L}]=534.91 \mathrm{EC}[\mathrm{dS} / \mathrm{m}]-12.66 ; \mathrm{R}^{2}=0.89\right)$.

Volumetric soil water content and salinity showed seasonal variation. Wetter conditions were measured during the rainy winter season compared to summer. In general, during the dry summer period, higher salinity values were recorded in the near surface soil layers compared to deeper layers, whilst in winter this pattern appeared to change. Salinity had an overall tendency to increase during the rainy period, possibly due to dissolution and mobilization of salts. This indicates an unusual pattern of soil salinity profiles, maybe due to the source of salts being the subsurface material. More seasons of monitoring will, however, be required in order to describe typical salinity patterns in this environment. Generally, wetter conditions and higher salinities were recorded at site 2 (SouthEast-oriented, clay soil) compared to site 1.

Fig. 3 shows water levels and salinity measured with an Eijkelkamp CTDDiver during a runoff event that occurred on 21 July 2006 (DoY = 202). Water level data were compensated for atmospheric pressure measured with the Baro Diver. A sudden increase in water level was initially observed due to saline runoff water leaking into the tank. As the event progressed, the water level of the tank reached a maximum level and overflow into the second tank occurred, whilst salinity remained constant indicating an influx of runoff water with steady salinity. No initial flush of salts was observed, nor salinity decreased as the runoff event progressed. Similar results were obtained for other runoff events in the period from June to September 2006. This is due to the nature of rainfall in the area, where events are typically steady, of long duration and generally relatively low intensity.

Measurements of EC in runoff and dam water are shown in fig. 4. Measurements of EC in runoff water were below $2 \mathrm{dS} / \mathrm{m}$. The general trend was that peaks of salinity tended to occur in the middle of the rainy season, when most rainfall and runoff events are likely to occur. Some tails of high salinity were also observed at the end of the rainy season. No "first flush" of salts was observed at the beginning of the season, due to the nature of rainfall (low intensity) and possibly the source of salts being below the surface. Salinity in dam water increased during the summer months as the water level in the dam decreased (fig. 4). The peak in salinity in dam water was $6.33 \mathrm{dS} / \mathrm{m}$ measured on 


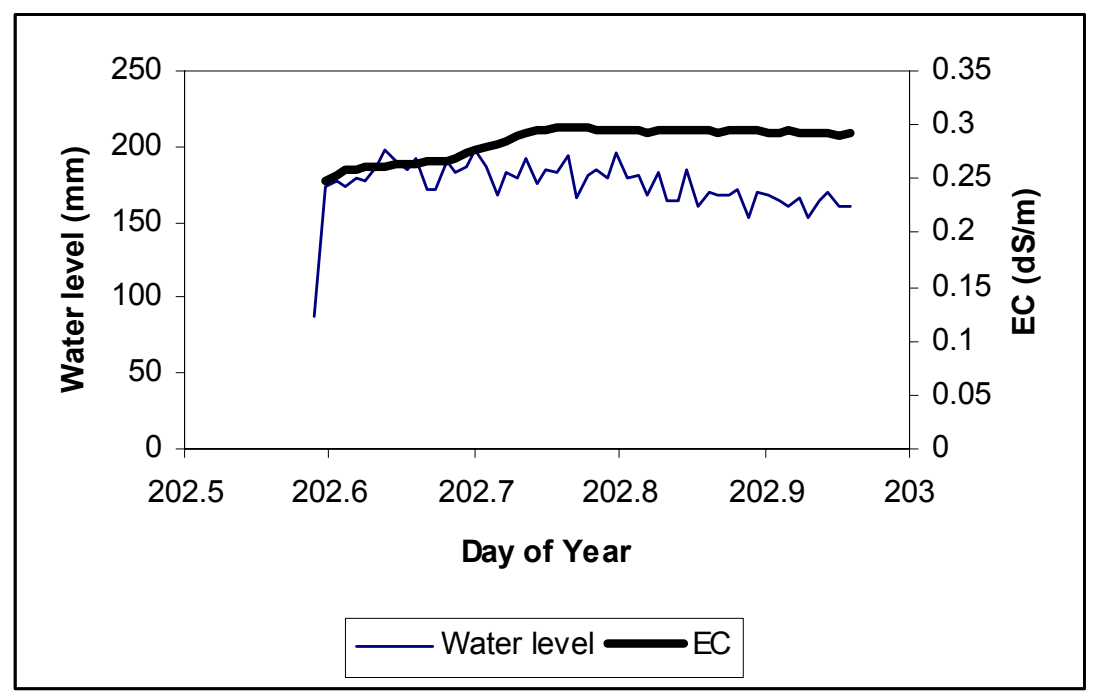

Figure 3: Water level and electrical conductivity (EC) in the first tank of the bare soil runoff plot at site 1 , during a runoff event that occurred on 21 July $2006($ DoY $=202)$.

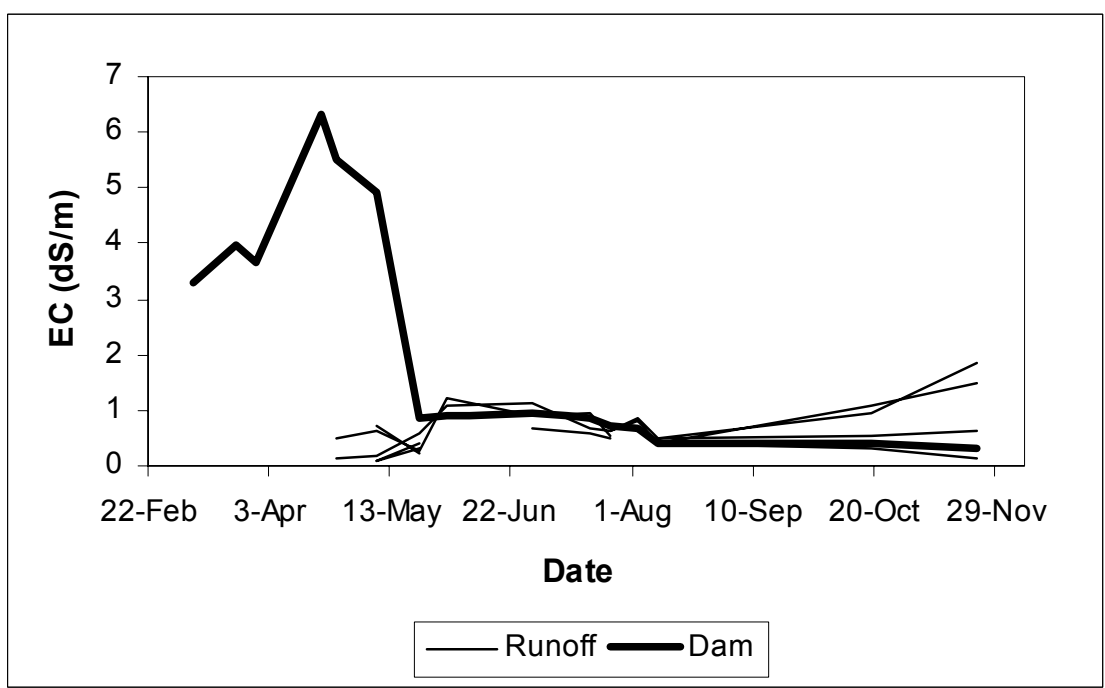

Figure 4: Electrical conductivity (EC) in runoff and dam water measured during 2006.

20 April 2006. This was recorded just before the onset of the 2006 winter season. Salinity in dam water decreased sharply with the onset of the rainy season in 2006. The salinity fluctuations in dam water were less pronounced compared to 
those measured in runoff water (fig. 4). This indicates that buffering of extreme events can be expected by increasing the scale of observation.

Runoff volumes and salinity measurements in runoff water collected in the tanks were used to calculate the amount of salts mobilized through overland flow. The data are summarized in table 1 for nine runoff events that occurred in the period from $25 / 04 / 2006$ to $10 / 08 / 2006$. During this period, total rainfall was $343 \mathrm{~mm}$. Variations in runoff volumes and salinity were recorded at the different runoff plots, depending on land use, soil properties, slope and orientation. It was evident from the data that more runoff occurred from the uncultivated plot compared to the vegetated plot at site 1 . At site 2 , large differences in runoff and total salts mobilized were observed from the same land use, possibly due to uneven re-growth of vegetation. Site 2 produced more runoff and generated more salts compared to site 1 due to wetter conditions on the South-East-facing slope, more clayey soil and steeper slope. It was also noticeable that more runoff was generally associated with higher salinity. Most rain water samples had an EC below $0.1 \mathrm{dS} / \mathrm{m}$. From total rainfall records and its salinity, one can deduce that the salt input to the SSC from rainfall was not sufficient to account for the quantities of salts being measured in overland flow. This strongly suggests that geology is playing a major contributing role as a source of salts.

Table 1: $\quad$ Total runoff volumes and salts mobilized through overland flow from $25 / 04 / 2006$ to $10 / 08 / 2006$.

\begin{tabular}{|l|l|c|c|c|}
\hline Location & Land use & $\begin{array}{l}\text { Slope } \\
(\%)\end{array}$ & $\begin{array}{l}\text { Runoff } \\
(\mathrm{mm})\end{array}$ & $\begin{array}{l}\text { TDS } \\
\left(\mathrm{g} \mathrm{m}^{-2}\right)\end{array}$ \\
\hline \multirow{2}{*}{ Site $1^{\mathrm{a}}$} & Bare soil & 9.1 & 31 & 11 \\
\cline { 2 - 5 } & Pasture & 9.1 & 9 & 2 \\
\hline \multirow{2}{*}{ Site $2^{\mathrm{b}}$} & Pasture & 12.4 & 61 & 24 \\
\cline { 2 - 5 } & Pasture & 12.4 & 21 & 5 \\
\hline
\end{tabular}

${ }^{a}$ North-oriented, sandy clay loam soil overlying Malmesbury shale.

${ }^{\mathrm{b}}$ South-East oriented, clay loam soil.

The movement of water and solutes in the vadose zone was simulated using the HYDRUS-2D model [12] for both monitoring sites from 01/01/2006 to $30 / 08 / 2006$. The purpose was to estimate the volumes of water and masses of salts that are mobilized via throughflow due to the formation of temporary water tables, in particular at site 1 where the Malmesbury shale restricts free drainage. Inputs to the model were: length of hillslope, depth of soil profile as well as slope (in order to design the geometry of the system); soil physical properties, rainfall, grass evapotranspiration for fallow land and linear density distribution of the root system; amounts of salts contributed via rainfall, throughflow and from the Malmesbury shale based on rain water and soil salinity measurements. The boundary conditions of the system were: i) atmospheric boundary at the top; ii) variable pressure at the vertical face up-slope (input data of volumetric soil water content converted into pressure values were used); iii) seepage face at the vertical face down-slope; and iv) constant flux boundary at the bottom for site 1 
(calibrated against soil water content data as the hydraulic conductivity of the Malmesbury shale is very low) and free drainage at site 2 .

The first step was to ensure an acceptable simulation of soil water fluxes and contents by comparison with field measurements. The model's soil water contents followed measured trends during winter (from June to August 2006). Concentrations of salts in the soils were then simulated. Fig. 5 shows the total simulated amount of salts that were flushed out of the soil profile at site 1 through the seepage face boundary, due to lateral fluxes on top of the Malmesbury shale (bottom boundary condition with low hydraulic conductivity). For the simulation period, a total of $695.56 \mathrm{~g} / \mathrm{m}$ per unit width was calculated to have been mobilized. The salts started flushing out of the profile only towards day of year 190, when the bottom of the soil profile neared saturation. The results of the simulation at site 2 showed that no salts were flushed from the soil profile through the seepage face boundary. Salts were lost from this profile only through the free drainage bottom boundary. From this, one can deduce that the presence of restricting layers, as is the case with site 1 , influenced the movement of water and salts. From the results of the simulations, one can also deduce that salts are mainly flushed into water bodies during winter, when the area receives most of its rainfall. In summer, the profile is then concentrated with salts as evaporation is the dominant salt mobilizing agent. Measured and simulated volumes of water and salts generally followed similar trends. Some discrepancies were due to spatial variability of the measurements, and the assumptions made in the model on the constant sources of salts originating from rainfall, throughflow and underlying geology.

\section{Conclusions}

Field measurements and the HYDRUS-2D model were used to estimate hydrosalinity fluxes in a small scale catchment of the Berg river for different soil properties, slopes, slope orientation and land uses. Besides gaining understanding on salt generation and transport mechanisms and quantification of hydrosalinity fluxes, the data collected in this field experiment will serve to inform modeling at the larger scale (quaternary catchment) in the next phase of research. In order to integrate runoff over a larger scale, homogeneous hydrological units need to be established and set up in hydrological models. The main criteria for homogeneity should be the geology, land use and slope. The subsurface fluxes were expressed for a $1 \mathrm{~m}^{2}$ cross section. The data could be extrapolated to a larger scale, provided the subsurface fluxes of the various soils, flow paths, and aquifer dimensions and characteristics are known. The cross section of flow at the Goedertrou SSC could occur along the length of the waterway from perched water tables on both slopes of the catchment. The ultimate aim will be to guide the development of land use management that would reduce the degradation of land and water resources (e.g. restoring native perennial deep-rooted vegetation, alley cropping, farming salt tolerant species or species capable of dewatering the soil to reduce groundwater recharge etc.). 


\section{Cumulative Seepage Face Solute Flux}

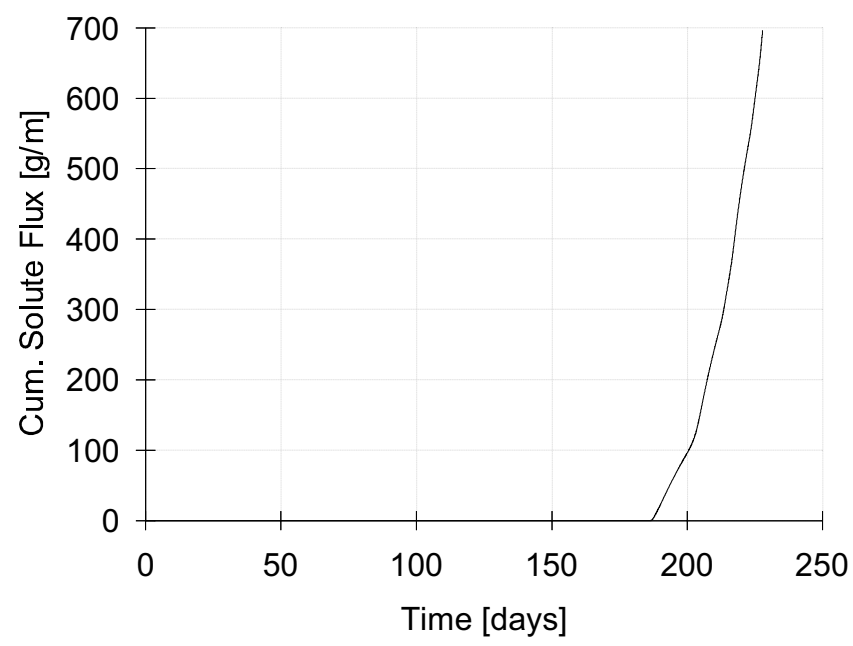

Figure 5: Simulation results representing the amounts of salts flushed from the soil profile (through subsurface flow and the seepage face) at site 1 for the period 01/01/2006 to 30/08/2006.

\section{Acknowledgement}

The authors wish to acknowledge financial support of the Water Research Commission (Pretoria, South Africa).

\section{References}

[1] Hingston, F.J. \& Gailitis, V., The geographic variation of salt precipitated over Western Australia. Australian Journal of Soil Research, 14, pp. 319 335, 1976.

[2] Acworth, R. I. \& Jankowski, J., Salt source for dryland salinity-evidence from an upland catchment on the Southern Tablelands of New South Wales. Australian Journal of Soil Research, 39, pp. 39-59, 2001.

[3] Greiner, R., Catchment management for dryland salinity control: Model analysis for the Liverpool Plains in New South Wales. Agricultural Systems, 56(2), pp. 225-251, 1998.

[4] Clarke, C. J., George, R. J., Bell, R. W. \& Hatton, T. J., Dryland salinity in south-western Australia: its origins, remedies, and future research directions Australian Journal of Soil Research, 40, pp. 93-113, 2002.

[5] Department of Water Affairs and Forestry, Hydrology of the Berg River Basin, R.R. Berg (Ninham Shand) in association with BKS Inc., Department of Water Affairs and Forestry, Report No. PG000/00/2491: Pretoria, South Africa, 1993. 
[6] Fourie, J.M., Mineralization of Western Cape rivers. PhD thesis: University of Stellenbosch, South Africa, 1976.

[7] Görgens, A.H.M. \& de Clercq, W.P., Summary of Water Quality Information System and Soil Quality Studies, Water Research Commission report No. TT252/05: Pretoria, South Africa, 2005.

[8] Flugel, W.A., River salinity due to dryland agriculture in the Western Cape Province, Republic of South Africa. Environment International, 21(5), pp. 679-686, 1995.

[9] Fey, M.V. \& de Clercq, W.P., Dryland Salinity Impacts on Western Cape Rivers, Water Research Commission report No. 1342/1/04: Pretoria, South Africa, 2004.

[10] Soil Classification Working Group, Soil Classification. A Taxonomic System for South Africa, Dept. of Agricultural Development: Pretoria, South Africa, 1991.

[11] FAO, World Reference Base for Soil Resources, Food and Agricultural Organization of the United Nations: Rome, Italy, 1998.

[12] Simunek J., Sejna, M. \& Van Genuchten, M.Th., The HYDRUS-2D Software Package for Simulating Two-Dimensional Movement of Water, Heat, and Multiple Solutes in Variably-Saturated Media, Version 2.0, U.S. Salinity Laboratory, USDA, ARS: Riverside, California, 1999. 